\title{
EDITORIAL
}

\section{Artículo científico: pautas para redactar la discusión}

La "discusión" es el corazón del manuscrito, talvez la sección más compleja de elaborar y organizar, refleja la madurez científica del investigador.

Un manuscrito con buenos resultados y una buena discusión, asegura su publicación. La discusión es donde la mayoría de los lectores irán después de leer el título y el resumen, y donde se pone a prueba la experiencia y madurez científica de un investigador.

A continuación, algunas consideraciones importantes a tener en cuenta al redactar la discusión:

a. Interpretación de resultados: Interpretar significa darle sentido a lo observado, equivale a decir el significado de un resultado. Esta interpretación se puede hacer con los propios resultados del estudio o con literatura previamente revisada.

b. Comparación de resultados: Aquí, compare sus resultados con resultados de la literatura y discuta si ellos están en concordancia o discordancia. Cuando la comparación indica discrepancia se tiene que buscar una explicación, esta explicación podría basarse en el propio estudio o en estudios previos. Cuando la comparación indica concordancia, se podría decir simplemente que hay consistencia con los resultados que reporta la literatura. En cualquier situación utilice la literatura científica que soporte la redactado.

c. Resalte el valor de los resultados: Resalte las excepciones y los puntos que todavía no pueden o no fueron suficientemente esclarecidos por los resultados. Sugiera nuevas posibilidades, plantee ideas para nuevos estudios, importancia de sus resultados y/o donde ellos pueden ser empleados.

Ph D. Raúl Siche 